\title{
Caracterização Flúvio-morfológica e Dinâmica da Paisagem da Sub-Bacia do Rio Ribeirão Santana - Rio Pardo de Minas/MG
}

Fluvio-morphology and dynamic characterization of the landscape of Santana River sub-basin - Rio Pardo de Minas/MG

\author{
Lioclécio Mendes de Souza', Fernando Hiago Souza Fernandes², César Vinícius Mendes Nery³, \\ Odilene Antunes Ribeiro'
}

\author{
' Discente do curso de Ambiental pelas Faculdades Santo Agostinho - FACET, Montes Claros, MG - Brasil. \\ 2 Engenheiro Ambiental pelas Faculdades Santo Agostinho - FACET, Instituto Biotrópicos - Bolsista (CNPq), Januária, MG - Brasil. \\ ${ }^{3}$ Professor M.Sc. das Faculdades Santo Agostinho, Doutorando em Geografia, PUC Minas, Montes Claros, MG - Brasil.
}

\begin{abstract}
Resumo
A caracterização morfométrica de bacias hidrográficas deve fornecer subsídios para o manejo eficiente dos recursos naturais. Neste sentido, o objetivo deste trabalho foi avaliar os aspectos morfométricos e caracterizar os principais usos e ocupação do solo na sub-bacia do rio Ribeirão Santana no município de Rio Pardo de Minas, norte de Minas Gerais. Para obtenção dos objetivos propostos foi utilizado dados altimétricos da folha $15 \mathrm{~S} 435 \mathrm{ZN}$ do projeto Topodata e imagens do satélite Landsat 8 com as respectivas bandas e suas composições 4(B), 5(G) e 6(R). Para o mapeamento da superfície utilizou-se classificador supervisionado, pixel a pixel de máxima verossimilhança (MAXVER) com limiar de aceitação de $99 \%$, sendo definidas as seguintes classes; cultura, mata ciliar, pastagem, vegetação e solo exposto. Os resultados encontrados sobre os aspectos morfométricos indicaram que a sub-bacia apresenta formato alongado, com coeficiente de compacidade de 1,93 , fator de forma de 0,366 , índice de circularidade de 0,262 e densidade de drenagem de $0,27 \mathrm{~km} / \mathrm{km}^{2}$. Dentre as classes determinadas pode se verificar a sua maior representação para áreas de pastagens (14.943 ha) e vegetação natural 27,30\%. Assim, verificou-se que a sub-bacia do Ribeirão Santana encontra-se relativamente preservada e com uma menor ameaça de enchentes em condições normais de precipitação.
\end{abstract}

Palavras-chave:Bacia hidrográfica, morfométria, uso e ocupação do solo.

\begin{abstract}
The morphometric characterisation of river basins must provide subsidies for the efficient management of natural resources. In this regard, the aim of this study was to evaluate the morphometric aspects and characterize the main uses and soil occupation on the sub-basin of Santana river in the municipality of Rio Pardo de Minas, north of Minas Gerais State. To obtain the objectives proposed altimetry data of sheet 15S435ZN from Topodata project was used and Landsat 8 satellite images with their respective bands and its compositions 4 (B), 5 (G) and 6 (R). For the mapping of the surface a supervised classifier was used, pixel to pixel Maximum Likelihood (MAXVER) with 99\% of acceptance threshold, the following classes are defined; cultivation, riparian forest, grassland, vegetation and exposed.soil The results found on the morphometric aspects indicated that the sub-basin presents elongated shape, with coefficient of compactness of 1.93 , form factor of 0.366 , index of circularity of 0.262 and drainage density of $0.27 \mathrm{~km} / \mathrm{km}^{2}$. Among the classes greater representation for grazing areas (14,943 ha) and natural vegetation 27.30 can be verified. Thus, it was found that the sub-basin of Santana river is relatively preserved and with a lower threat of flooding under normal conditions of precipitation.
\end{abstract}

Keywords: river basin, morphometry, soil use and occupation. 


\section{INTRODUÇÃO}

O uso insustentável dos recursos naturais vem sendo realizado ao longo dos anos, promovendo alterações na superfície terrestre e o desequilíbrio sobre as fontes de recursos naturais (ZACCHI et al., 2012).

Umas das maneiras de se avaliar as modificações causadas pelo uso antrópico é quando se utiliza a bacia hidrográfica como forma de planejamento, pois esta unidade permite que se consiga compreender de uma melhor maneira as alterações sofridas sobre a paisagem de uma área e assim avaliar os diferentes graus de antropização (TUCCI e MENDES, 2006).

A sub-bacia do Ribeirão Santana, situada no município de Rio Pardo Minas norte do estado Minas Gerais, apresenta-se como uma bacia de fundamental importância para o desenvolvimento econômico e social da região, uma vez que, a água do curso hídrico é utilizada para suprir as necessidades humanas de pequenas comunidades rurais localizadas em seu interior e suas terras são utilizadas para o sustento das famílias com o cultivo de pequenas e grandes culturas como, cana-de-açúcar, mandioca/ aipim, feijão e eucalipto (LEITE et al., 2012).

Nesse sentido, faz se necessário o uso de novas ferramentas capazes de auxiliar as alterações sobre a paisagem natural, pois a ausência de planejamento no uso da terra de uma região, objetivando máximos lucros com mínimos custos, sem a preocupação com o ambiente, pode acarretar consequências negativas à sociedade (GOLVEIA et al., 2013).

Dentre as ferramentas utilizadas para análise da compreensão de uma superfície terrestre e suas conexões os dados por meio das técnicas do sensoriamento remoto apresentam-se vantajosos pela facilidade de aquisição e rápido processamento digital dos mesmos, permitindo assim, que se consiga verificar a atual situação do uso e ocupação do solo, bem como estudar variáveis morfométricas de uma bacia hidrográfica (MENESES, 2012).

Estudos comprovam que as características morfométricas são de grande importância, pois apontam a dinâmica presente da bacia ligando os sistemas hidrológicos com o sistema ambiental e social, podendo evidenciar os tipos de processos naturais ou antrópicos, que tendem a ser mais intensos no meio ambiente e prever o grau de vulnerabilidade da bacia a fenômenos extremos como enchentes e inundações (LOURENÇO et al., 2013).

Neste contexto, objetivou se com este trabalho avaliar os aspectos morfométricos da sub-bacia do Ribeirão Santana a partir da base de dados das imagens SRTM em virtude da escassez de dados morfométricos dessa sub-bacia e de identificar o atual uso e ocupação do solo por meio de imagens de satélite de forma a subsidiar em um melhor planejamento da superfície terrestre e uma melhor tomada de decisão por parte dos gestores.

\section{REFERENCIAL TEÓRICO}

A caracterização prática e integrada de bacias hidrográficas pressupõe planejar e implantar as práticas de manutenção e conservação, visando uma proteção e valorização ambiental e social para o desenvolvimento sustentável considerando-se o contexto das bacias e não nas propriedades isoladas. O elemento de planejamento passa a ser a bacia hidrográfica (COSTA e GOMES, 2013).

De acordo, com a Lei de $\mathrm{n}^{\circ} 9.433$ (BRASIL, 1997), bacia hidrográfica pode ser considerada como uma unidade territorial de gestão para implementação da Política Nacional de Recursos Hídricos e atuação do Sistema Nacional de Gerenciamento de Recursos Hídricos.

Segundo Pinto et al. (1976), bacia hidrográfica ou bacia de contribuição de uma seção de um curso de água é um espaço geográfico coletor de água de precipitação que, escorre pela sua superfície, atingindo os leitos tributários para o canal principal. Desta forma, é necessário destacar o importante papel exercido pelo tipo de cobertura e uso da bacia para avaliar o comportamento hidrológico na localidade.

A caracterização do sistema ambiental de uma bacia hidrográfica pode esclarecer as várias questões pertinentes com a percepção da dinâmica ambiental local que constituem uma notável fonte de informações para a compreensão física da bacia e a ação das terras drenadas por ela, certamente quando o ambiente em questão está sofrendo modificações em parte de seu curso d'água (FEITOSA et al., 2011). 
O estudo detalhado de uma bacia seja de suas características físicas, parcelamento do solo, uso e ocupação, social e econômica é fundamental a utilização e manejo mais adequado dos seus recursos. Essa vulnerabilidade ambiental pode ser compreendida como risco de degradação do ambiente natural relacionada á erosão, perda da biodiversidade, assoreamento, contaminação dos recursos naturais (ABREU et al., 2013).

As análises morfométricas abrangem um grande número de parâmetros que permite melhor caracterização do ambiente da bacia, sua predisposição a ocorrência de alguns eventos e sua incompatibilidade com certas atividades humanas e/ou com alguns modelos de uso e ocupação do solo (CHRISTOFOLETTI, 1999). Muitos desses parâmetros são aplicados com indicadores de degradação ambiental no qual determinada bacia pode esta exposta, podendo avaliar sua suscetibilidade á ocorrência de eventos ligados a processos erosivos e inundações (MACHADO e TORRES, 2012).

As características morfométricas apresentam então, dados importantes para análise do comportamento da paisagem sobre um espaço geográfico, desta forma há diversos mecanismos para que se possam avaliar as alterações e suas formas, dente eles, destacam-se a densidade de drenagem, fator de forma, coeficiente de compacidade, índice de compacidade e outras (BRUBACHER et al., 2012).

O sistema de drenagem correlaciona o comprimento total dos canais ou rios com a área da bacia hidrográfica tanto os principais e seus tributários, ver equação 1 (HORTON, 1945), apud (MACHADO e TORRES, 2012),

$\mathrm{Dd}=\mathrm{Lt} / \mathrm{A}$

equação (1)

Dd: densidade de drenagem (km/km2); Lt: comprimento total de todos os canais (km); A: área de drenagem (km2).

O fator de forma é a relação entre a largura média da bacia e o comprimento axial do curso d' água. O comprimento é medido seguindo-se o curso d' água mais longo desde a cabeceira mais distante da bacia até o exutório (OLIVEIRA, 2010).

Segundo Villela e Matos (1975), uma bacia com um fator de forma baixo é menos sujeita a enchentes do que outra de mesmo tamanho, porém com fator de forma maior. $\mathrm{O}$ fator de forma pode ser descrito pela equação 2 .

$\mathrm{Kf}=\mathrm{A} / \mathrm{L}^{2}$

equação (2)

$\mathrm{Kf}$ - fator de forma; $\mathrm{A}$ - área de drenagem, $\mathrm{m}^{2} ; \mathrm{L}$ - comprimento do eixo da bacia, $\mathrm{m}$.

Relaciona que, para uma bacia circular ideal, quanto maior for índice de compacidade Kc maior será sua irregularidade no terreno, sendo este representado por um número adimensional que varia com a forma da bacia. Um coeficiente mínimo igual a um corresponderia a uma bacia circula, podendo ser calculado pela equação 3 (GARCEZ e ALVARES, 2013).

$\mathrm{Kc}=0,28 * \mathrm{P} / \sqrt{ } \mathrm{A}$

equação (3)

$\mathrm{Kc}$ - coeficiente de compacidade; $\mathrm{P}$ - perímetro da bacia, $\mathrm{m}$; $\mathrm{A}$ - área de drenagem, $\mathrm{m}^{2}$.

Simultaneamente ao coeficiente de compacidade, o índice de circularidade tende para unidade à medida que a bacia aproxima-se a forma circular e diminui a medida que a forma torna alongada, segundo a equação 4 (CARDOSO et al., 2006):

$\mathrm{IC}=12,57 * \mathrm{~A} / \mathrm{P}$

equação (4)

IC - índice de circularidade; $\mathrm{A}$ - área de drenagem, $\mathrm{m}^{2} ; \mathrm{P}$ - perímetro, $\mathrm{m}$.

De acordo com Ferreira et al. (2010), ao utilizar técnicas de sensoriamento remoto, para obtenção de um panorama da paisagem de uma dada área, torna-se imprescindível a análise espacial e mapeamento desta, de maneira que se consiga um diagnóstico das principais usos do solo e suas mudanças em serie temporal.

O processo de classificação de imagens digitais se baseia em atribuir características presentes na imagem a uma determinada classe desejada (FLORENZANO, 2011). A classificação pode supervisionada e não supervisionada, de acordo com o grau de intervenção do interprete (NOVO, 2010), e ainda esta pode se dar por análise de um agrupamento de pixels, sendo a classificação por regiões, ou 
pela análise espectral isolada de cada pixel, a classificação pixel a pixel (NERY et al., 2013).

O algoritmo de Máxima Verossimilhança (MAXVER) é baseado na teoria de Bayes, assumindo desta forma, uma distribuição normal dos níveis de cinza dos pixels, caracterizando as diferentes classes da imagem pelo vetor média e a matriz de covariância, estimadas pelas amostras adquiridas (REMPEL, 2000).

De acordo com Meneses e Sano (2012), no algoritmo MAXVER cada pixel é avaliado à classe que tem a maior probabilidade. Isso significa que para um pixel na posição $\mathrm{x}$ do espaço multiespectral, um conjunto de probabilidades são computadas e que dão as possibilidades relativas do pixel pertencer a cada classe disponível $\left(p\left(x \mid \omega_{i}\right)\right)$.

\section{MATERIAIS E MÉTODOS}

A sub-bacia do Ribeirão Santana esta localizada entre as coordenadas $16^{\circ} 12^{\prime} 00 \mathrm{~S} ; 5^{\circ} 35^{\prime} 00$ N, 42 $48^{\circ} 00$ W; $42^{\circ} 12^{\prime} 00$ E no município de Rio Pardo de Minas ao Norte de Minas Gerais, segundo a classificação climática de Köppen, o clima predominante na região é Aw - inverno seco e chuvas máximas no verão, comprovando assim, a necessidade de alternativas de preservação para a manutenção dos recursos hídricos.
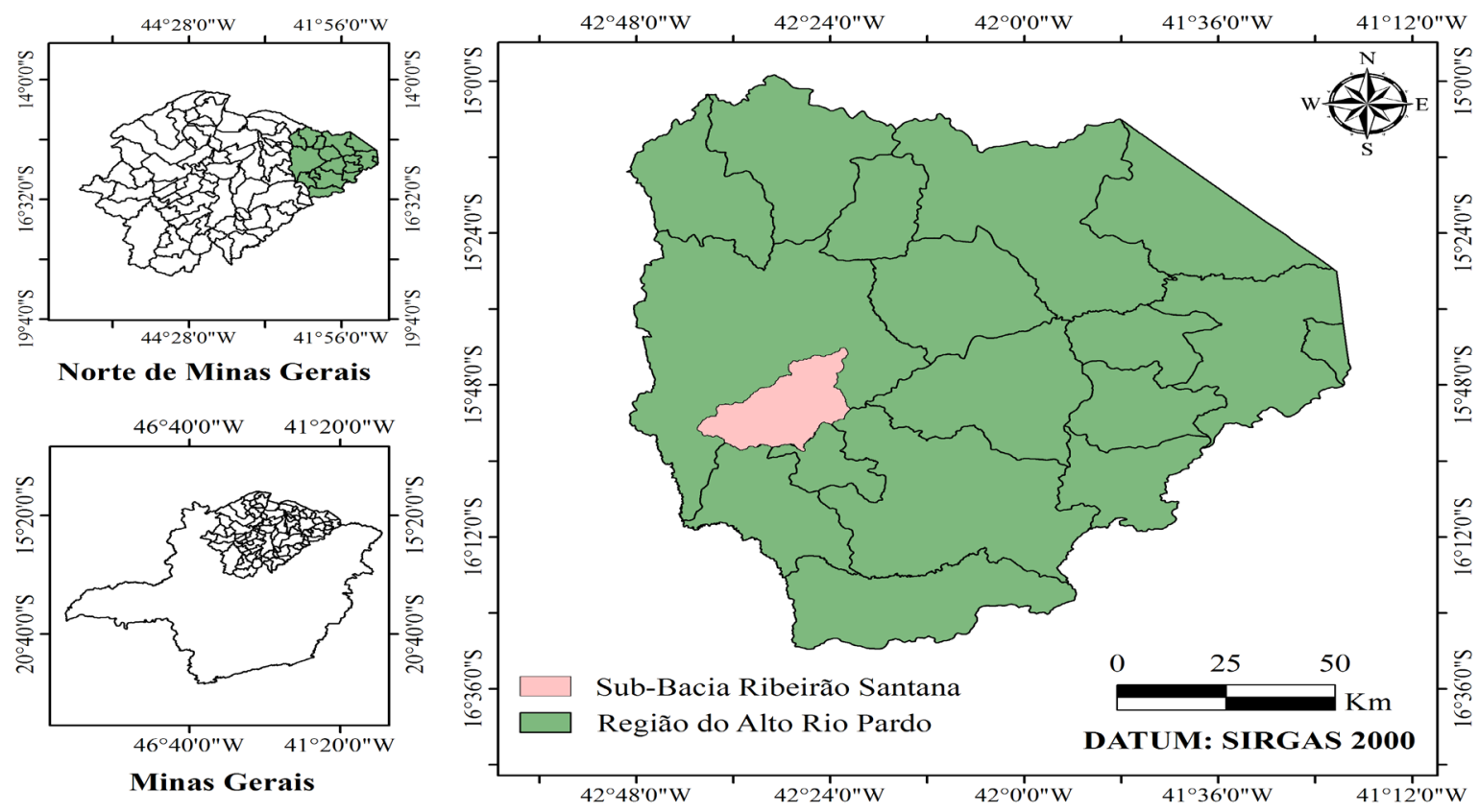

Figura 01 - Localização geográfica da sub-bacia do rio Ribeirão Santana, Rio Pardo de Minas, MG. Fonte: Próprio Autor.

A sub-bacia tem aproximadamente uma área total de 52.852 ha (Figura 1), sendo um dos principais afluentes do Rio Pardo na região.

O município de Rio Pardo de Minas possui uma área de 3.117,437 Km2, com uma população de 29.099 habitantes, sua economia é baseada principalmente por serviços, agropecuária e indústrias de médio e pequeno porte. $\mathrm{O}$ aspecto geral do seu território é montanhoso, situado próximo a Serra Geral, no alto da bacia do Rio Pardo, com predominância do bioma Cerrado e alguns vestígios de Mata Atlântica o município e banhando por dois grandes rios o Pardo e o Preto, situado na microrregião do Alto Rio Pardo (IBGE, 2010), sendo a água do rio Pardo responsável pelo abastecimento público de água para a cidade de Rio Pardo de Minas (COPASA, 2014).

Utilizando-se da plataforma TerraHidro, que é um aplicativo do SIG TerraView foi delimitado a área da bacia hidrográfica do rio Ribeirão Santana (LIMA et al., 2012), de posse dos dados altimétricos da folha $15 \mathrm{~S} 435 \mathrm{ZN}$ do projeto TOPODATA.

Para a base metodológica deste trabalho foi utilizado o software ENVI 5.0 do Laboratório de Topografia, Cartografia e Geoprocessamento (LABGEO), das Faculdades de Ciências Exatas e 
Tecnológicas Santo Agostinho (FACET), com sistema de referência, latitude e longitude e modelo de terra, SIRGAS 2000.

As imagens utilizadas no processamento digital foram obtidas do sensor OLI/TIRS a bordo do satélite Landsat 8 oferecidas gratuitamente pelo site da USGS (http://earthexplorer.usgs.gov/) no formato GeoTiff com resolução espacial de 30 metros. Foram utilizadas duas cenas do sensor OLI/ TIRS em virtude da necessidade de um mosaico para análise da sub-bacia do rio Ribeirão Santana, de órbita-ponto 217-071; 218-071 com as respectivas passagens 01/07/13 e 22/06/13.

Para correção geométrica das cenas foi utilizado duas imagens ortorretificadas TM/Landsat-5 de órbita e ponto 217-071; 218-071. Após o registro das imagens foi feito a classificação das mesmas por meio do classificador supervisionado de máxima verossimilhança (MAXVER) com limiar de aceitação de $99 \%$, sendo as amostras de vegetação, solo exposto, cultura, mata ciliar e pastagem adquiridas pixel a pixel.

Após o processamento digital das imagens os resultados do mapeamento para o uso e ocupação do solo da sub-bacia do Ribeirão Santana foi realizado por meio do layout do ArcMap 10 no LABGEO - FACET.

Para a morfométria, diversos parâmetros foram analisados para obter as características físicas da sub-bacia, como, área de drenagem, perímetro da sub-bacia, comprimento total dos canais, comprimento total do canal principal, coeficiente de compacidade, fator de forma, índice de circularidade, altitude (mínima, media é máxima), ordem dos cursos d'aguas e densidade de drenagem. Para identificação das medidas do comprimento do canal principal e seus afluentes utilizou-se o software Trackmaker LABGEO - FACET.

A rede hídrica foi ordenada de acordo com Strahler (1957), que considera todos os canais sem tributários como de primeira ordem; os canais de segunda ordem, por outro lado, se originam da confluência de dois canais de primeira ordem; os de terceira ordem, por sua vez, se formam pela junção de canais de ordem 2 .

\section{RESULTADOS E DISCUSSÃO}

Os resultados da caracterização morfométrica da sub-bacia hidrográfica do Ribeirão Santana se encontram apresentados na Tabela 1. A área encontrada da sub-bacia foi de aproximadamente 528,52 $\mathrm{Km}^{2}$ e perímetro de $159,04 \mathrm{Km}$ se demostrando uma bacia de escala média com cerca de 16 córregos tributários ao longo do seu leito com comprimento total de $143 \mathrm{Km}$ e o curso hídrico principal Ribeirão Santana próximo aos $47 \mathrm{Km}$ que dá nome á sub-bacia.

Tabela 01: Características morfométricas da sub-bacia do rio Ribeirão Santana, Rio Pardo de Minas, MG.

\begin{tabular}{ll}
\hline Características Morfométricas & Valores \\
\hline Área de Drenagem $\left(\mathrm{Km}^{2}\right)$ & 528,52 \\
Perímetro $(\mathrm{Km})$ & 159,04 \\
Comprimento total dos canais, Lt $(\mathrm{Km})$ & 143 \\
Comprimento do canal principal L (Km) & 47,17 \\
Coeficiente de compacidade, Kc & 1,93 \\
Fator de forma, Kf & 0,366 \\
Índice de circularidade, IC & 0,262 \\
Ordem da Bacia & 3 \\
Altitude mínima (m) & 742 \\
Altitude media (m) & 883,5 \\
Altitude máxima (m) & 1.025 \\
Densidade de drenagem, Dd $\left(\mathrm{Km}, \mathrm{Km}^{2}\right)$ & 0,270 \\
\hline
\end{tabular}

Fonte: Próprio Autor.

A sub-bacia do Ribeirão Santana apresenta-se de terceira ordem, indicando ser pouco ramificada (TUCCI e MENDES, 2006). 
Os fatores que indicam a forma da sub-bacia relacionam com formas geométricas, pois demonstra a forma superficial da área de estudo, sendo de grande importância para determinação do tempo de concentração da precipitação, até o exutório da sub-bacia (VILELA e MATTOS, 1975), uma vez que quanto maior o tempo de concentração menor será a vazão em enchentes ou eventos extremos.

O coeficiente de compacidade de 1,93 demonstra a sua irregularidade, fator de forma de 0,366 indica que esta sub-bacia e menos susceptível a ocorrência de enchente não demonstrando uma forma circular (NARDINI et al., 2013). O resultado do cálculo do índice de circularidade corrobora essa conclusão. $\mathrm{O}$ valor resultante foi de 0,262 apresentado assim formato alongado, o que proporciona $\mathrm{o}$ amortecimento de eventos com grande volume de chuvas.

Em estudos realizados por Ferreira et al. (2013), sobre uma bacia hidrográfica entre os municípios de Uberlândia e Tupaciguara/MG encontraram-se valores semelhantes a este estudo com fator de forma para a sub-bacia do rio das Pedras de 0,17 , cálculo do coeficiente de compacidade de 1,54, e índice de circularidade de 0,42 indicando a existência de uma forma mais alongada e irregular, contribuindo para a menor incidência de enchentes.

De acordo Villela e Mattos (1975), os valores para densidade de drenagem normalmente variam entre $0,5 \mathrm{Km} / \mathrm{Km}^{2}$ em bacias com drenagem pobre, a $3,5 \mathrm{Km} / \mathrm{Km}^{2}$, ou mais, em bacias bem drenadas. Neste estudo, a densidade de drenagem foi de $0,27 \mathrm{Km} / \mathrm{Km}^{2}$, indica que a sub-bacia possui uma baixa capacidade de drenagem podendo ser devido à natureza dos solos locais, alta permeabilidade e de precipitações baixas (FEITOSA et al., 2011), uma vez que solos com baixo grau de desenvolvimento de seu sistema de drenagem, caracterizam em sua maioria por presença de rochas e solos muito permeáveis (KRAVCHENKO, 1998).

A altitude da região demonstrou que a área de estudo apresenta-se com valores elevados, variando entre $742 \mathrm{~m}$ é $1.025 \mathrm{~m}$ (Figura 2), podendo tonar o terreno mais vulneral por erosões, caso a vegetação natural seja suprimida próximas as linhas de cumeada da sub-bacia do rio Ribeirão Santana (NERY et al., 2013).
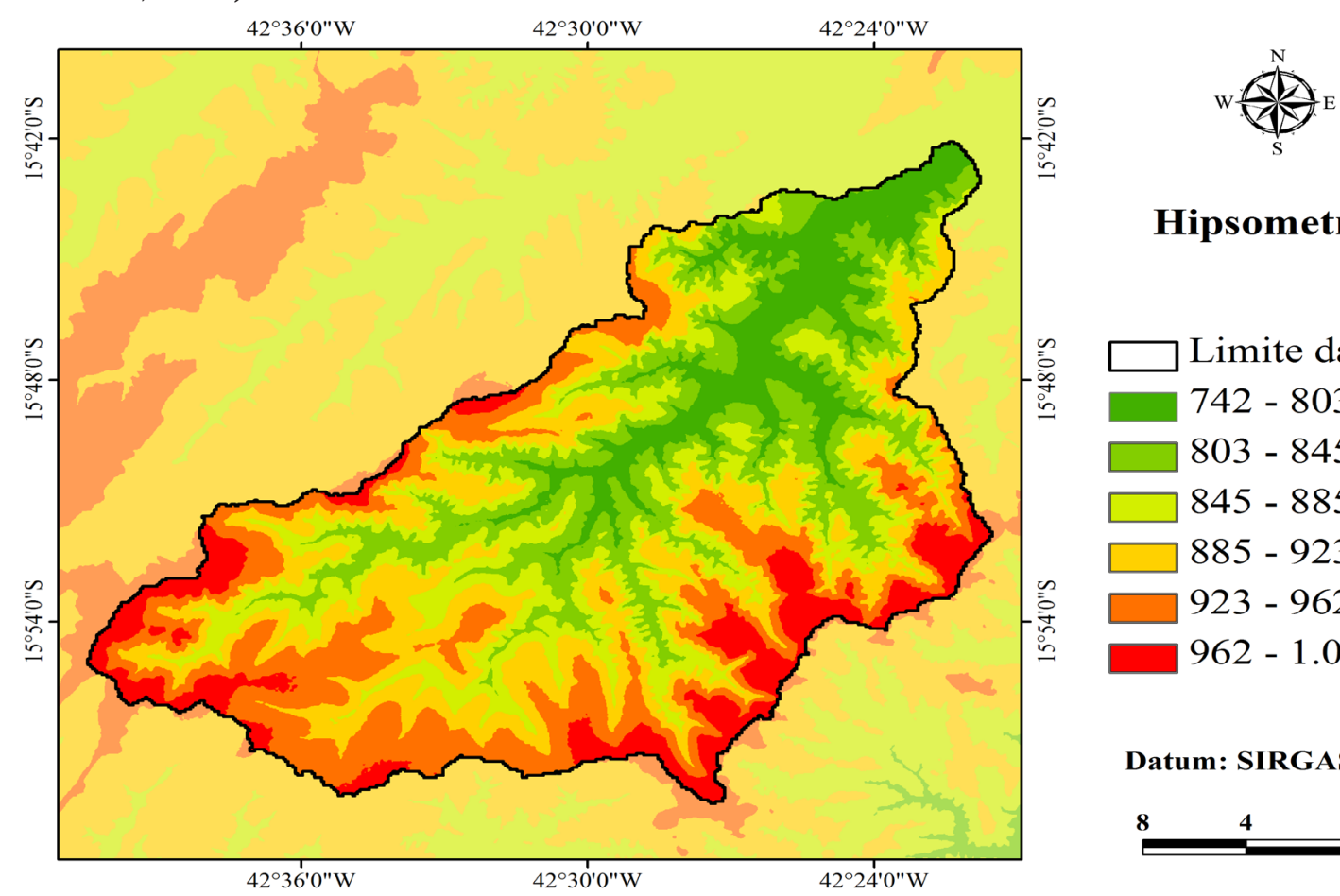

\section{Hipsometria}

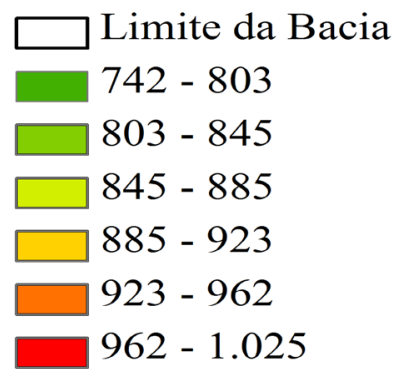

Datum: SIRGAS 2000

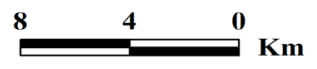

Figura 02 - Carta hipsômetrica da sub-bacia do Ribeirão Santana, Rio Pardo de Minas, MG.

Fonte: Próprio Autor.

Por meio da representação espacial do uso e ocupação do solo na sub-bacia do Ribeirão Santana (Figura 3), verificou-se que a classe pastagem foi a categoria de maior predominância com 14.953 ha, de fato esse valor encontrado na sub-bacia pode ser corrobado com os dados do produto interno bruto do município de Rio Pardo de Minas, sendo a atividade agropecuária responsável pela segunda maior 
fonte da econômica do município (IBGE, 2010).

Importante destacar que o valor expressivo para área de pastagens $28,30 \%$ podem ser justificadas por área anteriormente ocupadas por silviculturas, pois após a corte do eucalipto é predominado um tipo de espécie de forrageira "fura saco" na região da sub-bacia do Ribeirão Santana (VILELA et al., 2009), não descartando ainda que a resolução espacial da imagem de $30 \mathrm{~m}$ pode ter comprometido em uma melhor estratificação do uso e ocupação do solo, pois a reflectância espectral de uma única célula da imagem pode ser representada por uma mistura de objetos presentes na superfície terrestre (PONZONI et al., 2012).
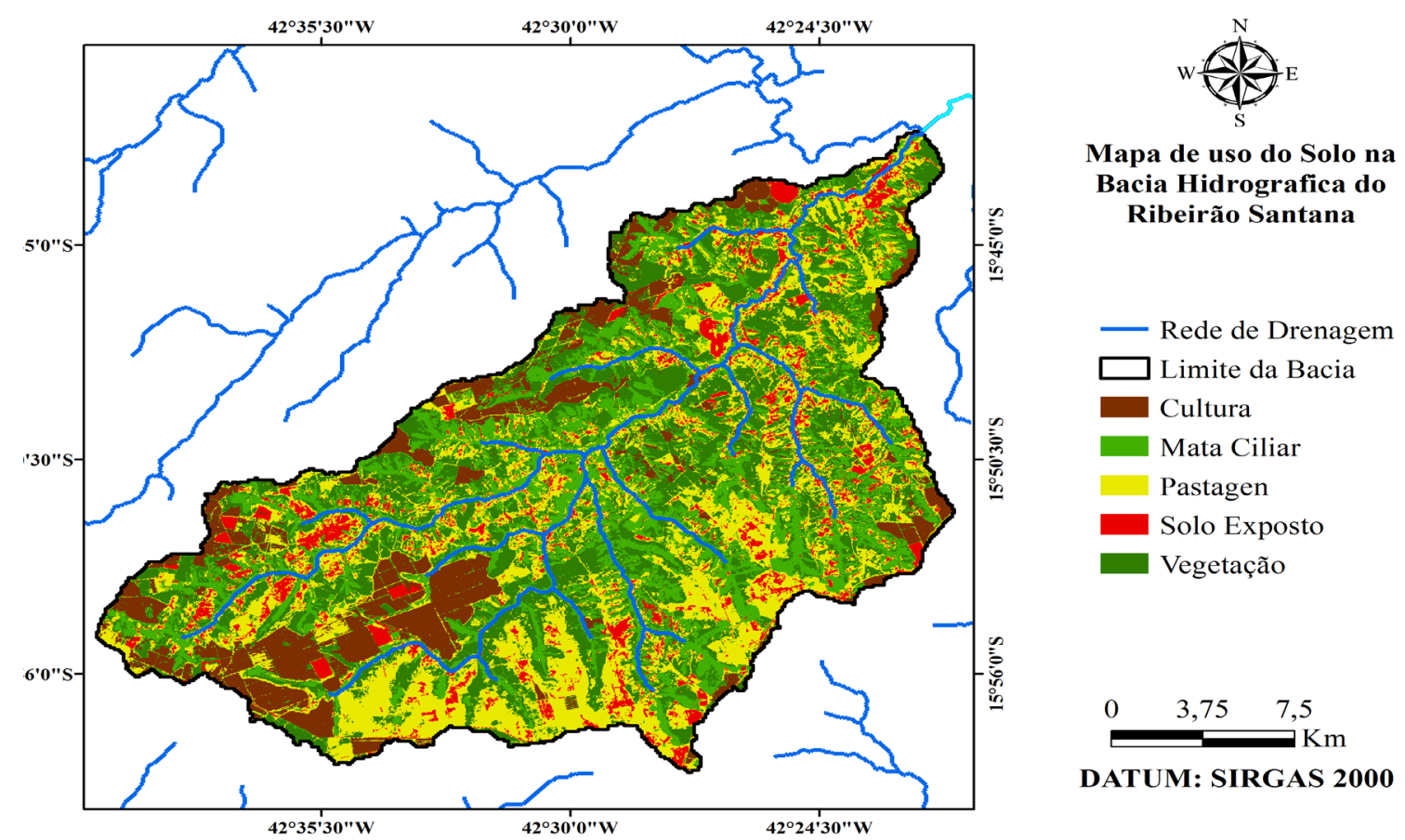

Figura 03 - Uso e ocupação do solo da sub-bacia do Ribeirão Santana, Rio Pardo de Minas, MG.

Fonte: Próprio Autor.

Em se tratando da classe cultura pode se perceber que das 4.425 ha $(8,37 \%)$ mapeadas (Figura 3 ), estas se encontram em sua maioria próximas ao limite da linha de cumeada da sub-bacia, em virtude das características morfológicas dessas áreas consideradas como chapadas com características elevadas e relevo plano suave-ondulado, onde predominam os grandes plantios de eucaliptos na região destinados a suprir energeticamente as siderúrgicas instaladas na região central do estado (LEITE et al., 2012; VILELA et al., 2009).

Considerando que a maior parte da população do município de Rio Pardo de Minas encontra-se no meio rural (IBGE, 2010) e que as atividades culturais como plantações de mandiocas, feijão, amendoim e algodão são predominantemente implantada desde os séculos passados para a subsistência da população local e região (VILELA et al., 2009), não foi possível verificar com grande exatidão estas áreas, pois a resolução da imagem limitou-se a identificação e caracterização desses tipos de cultura. Vale salientar, que as imagens utilizadas para o mapeamento do uso e ocupação do solo foram adquiridas em períodos secos e que a prática dessa atividade normalmente acontece em períodos chuvosos.

Por meio da (Figura 3) pode-se constatar ainda, que ás área de solo exposto acompanham a rede de drenagem da sub-bacia do Ribeirão Santana, a ocorrência dessa situação pode ser justificada em virtude de essas áreas apresentarem grande quantidade de matéria orgânica (MARTINS et al., 2013), sendo normalmente mecanizadas para implantação de culturas temporárias nos períodos chuvosos.

Diante dessas informações apresentadas é importante ressaltar que a prática da mecanização dos solos para o plantio de culturas intermitentes em períodos chuvosos pode acarretar o assoreamento dos cursos hídricos apresentando formações de sulcos, ravinas e até voçorocas, podendo ocasionar 
impactos ao ecossistema aquático (MARTINS et al., 2013). Vale ressaltar ainda, que as áreas próximas ao leito do curso hídrico são consideradas como áreas de preservação permanente (APP) definidas pela Lei Federal de ${ }^{\circ} 12.651$ de 25 de maio de 2012, considerando em art. $2^{\circ}$ estas área como, área que possuem a função ambiental de preservar os recursos naturais e assegurar o bem-estar das populações humanas (BRASIL, 2012), devendo desta forma, serem cobertas preferencialmente por formações vegetais nativas da região (NERY et al., 2013).

Outra forma que se caracteriza em área de solo exposto são as áreas de plantações de eucalipto, pois o corte da espécie deixa o solo desprotegido e vulnerável à ocorrência desta situação (LEITE et al., 2012).

Com relação às categorias vegetação e mata ciliar, estas representam um total de $50,5 \%$ da sub-bacia com 14.431 ha e 12.258 ha respectivamente (Figura 3). As representações dessas categorias evidenciam que a sub-bacia encontra-se parcialmente preservada (Figura 4), o que contribui de forma positiva para a biodiversidade local. Tal situação pode estar sendo vivenciada em consequência da redução das atividades de empresas reflorestadoras, pois a partir do ano de 2008 ocorreu a finalização dos contratos de comodato entre o governo estadual e empresas reflorestadoras assinados na década de 1970, contribuindo para o processo de regeneração natural da vegetação (VILELA et al., 2009).

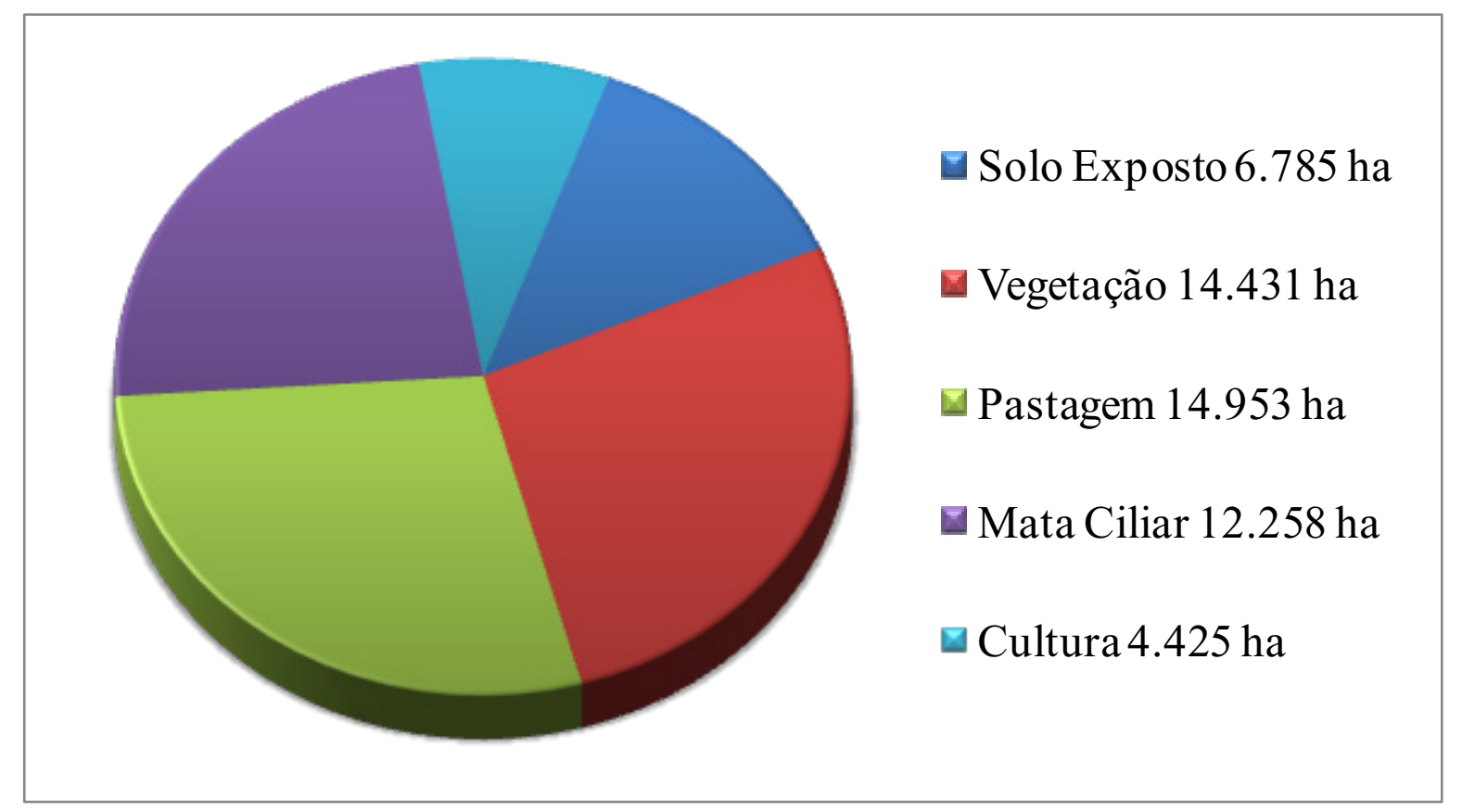

Figura 04. Gráfico com resultado do mapeamento do uso e ocupação do solo da sub-bacia do rio Ribeirão Santa.

Fonte: Próprio Autor.

Os resultados do mapeamento do uso do solo apresentados na figura acima (Figura 4) mostram que as áreas da sub-bacia apresentam-se relativamente modificadas pelo uso antrópico (49,5\%), apesar da grande representação espacial de áreas preservadas na sub-bacia do Ribeirão Santana.

\section{CONCLUSÃO}

Com base nos objetivos propostos pelo trabalho, chegou-se as seguintes conclusões a sub-bacia do Ribeirão Santana esta apresenta-se como uma bacia menos sujeita a catástrofes naturais, como enchentes. O uso do solo encontra-se parcialmente coberto por formações vegetais o que indica um relativo grau de preservação, no entanto é importante destacar que a perda da vegetação pode vir a ocasionar situações adversas para a população adstrita na sub-bacia.

Por meio das classes determinadas para o mapeamento da superfície terrestre utilizando-se da classificação supervisionada foi possível verificar o atual uso e ocupação do solo na sub-bacia do rio 
Ribeirão Santana, com a maior representação para as classes pastagem e vegetação e as menores para as categorias de cultura e solo exposto.

A análise dos dados e a interpretação dos resultados do índice de circularidade, coeficiente de compacidade e fator de forma da sub-bacia do Ribeirão Santana mostraram que a mesma possui uma forma alongada tendendo a menor ameaça de cheias em condições normais de precipitação.

A sub-bacia hidrográfica do rio do Ribeirão Santana é de terceira ordem do tipo dendrítico, apontando que o sistema de drenagem da bacia possui um sistema com baixo grau de ramificação.

Para uma melhor gestão é conservação dos recursos naturais na sub-bacia Ribeirão Santana recomenda-se que estudos posteriores sejam realizados incluindo, analises geomorfológicas, geológicas e pedológicas e que estudos utilizando-se da matriz de tabulação cruzada sejam realizados de maneira a identificar as principais alterações sobre a superfície do solo mostrando as variações líquidas entre categorias distintas e transferências de áreas de uma mesma entre dois momentos distintos. Neste contexto, os órgãos públicos dispõem agora de informações essências para um melhor gerenciamento do desenvolvimento sustentável da sub-bacia do rio Ribeirão Santana.

\section{AGRADECIMENTOS}

Os autores agradecem ao Núcleo Interinstitucional de Estudos Ambientais do Norte de Minas (NIEA-MN) e a Fundação Santo Agostinho.

\section{REFERÊNCIAS}

BRASIL, Lei n ${ }^{\circ}$ 9.433, de 8 de Janeiro de 1997 . Institui a Política Nacional de Recursos Hídricos, cria o Sistema Nacional de Gerenciamento de Recursos Hídricos, regulamenta o inciso XIX do art. 21 da Constituição Federal, e altera o art. $1^{\circ}$ da Lei ${ }^{\circ}$ 8.001, de 13 de março de 1990, que modificou a Lei no 7.990, de 28 de dezembro de 1989. Diário Oficial [da República Federativa do Brasil], Brasília, 08 jan. 1997. Disponível em: <http://www.mma.gov.br/port/conama/legiabre.cfm?codlegi=370>. Acesso em: 28 jan. 2014.

Lei $n^{\circ} 12.651$ de 25 de maio de 2012. Dispõe sobre a proteção da vegetação nativa; altera as Leis

nos 6.938, de 31 de agosto de 1981, 9.393, de 19 de dezembro de 1996, e 11.428, de 22 de dezembro de 2006; revoga as Leis nos 4.771, de 15 de setembro de 1965, e 7.754, de 14 de abril de 1989, e a Medida Provisória no 2.166-67, de 24 de agosto de 2001; e dá outras providências. Diário Oficial [da República Federativa do Brasil], Brasília, 28 mai. 2012. Disponível em: http://www.planalto.gov.br/ccivil_03/_Ato2011-2014/2012/ Lei/L12651.htm>. Acesso em: 20 maio 2014.

BRUBACHER, J. P. et al. Avaliação de bases SRTM para extração de variáveis morfométricas e de drenagem. Geociências, v. 31, n. 3, p. 381-393, jun. 2012. Disponível em: <http://ppegeo.igc.usp.br/pdf/geosp/v31n3/ v31n3a06.pdf>. Acesso em: 21 maio 2014.

CARDOSO, C, A. et al. Caracterização Morfométrica da bacia hidrográfica do Rio Debossan, Nova Friburgo, RJ. Sociedade de Investigações Florestais, v. 30, n. 2, p. 241-248, Nov. 2006. Disponível em: < hhttp://www. scielo.br/scielo.php?pid=S0100-67622006000200011\&script=sci_arttext >. Acesso em: $13 \mathrm{dez} .2013$.

COSTA, F. da S.; GOMES. S. O plano de gestão da região hidrográfica 2 : Contributo metodológico para a avaliação do programa de medidas a partir do caso da bacia hidrográfica do Rio Cávado. In: Congresso Ibérico de Gestão e Planeamento da Água, VIII., 2013, Lisboa. Anais... Lisboa: 2013. p. 793-801. Disponível em: $<$ http://repositorium.sdum.uminho.pt/handle/1822/26992?mode=full\&submit_simple=Mostrar+registo+em+formato+completo>. Acesso em: 27 maio 2014.

COPASA, Companhia de saneamento de Minas Gerais. Área de abrangência dos municípios usufruídos do serviço da Copasa, 2014. Disponível em: <http://www.copasa.com.br/cgi/cgilua.exe/sys/start.htm?- 
sid=22>. Acesso em: 09 mar. 2014.

CHRISTOFOLETTI, A. Modelagem de Sistemas Ambientais. São Paulo: Edgard Blucher, 1999.

FEITOSA, A.; SANTOS, B dos.; ARAÚJO, M, do S, B, de. Caracterização Morfométrica e identificação de Áreas Susceptíveis a Erosão na Bacia do Rio Pajeú, PE: o Estudo de Caso da Bacia do Rio Pajeú/PE. Revista Brasileira de Geografia Física, v. 04, n. 4, p. 820-836, dez. 2011. Disponível em: <http://www.revista.ufpe. br/rbgfe/index.php/revista/article/viewArticle/231>. Acesso em: 10 mar. 2014.

FERREIRA, M. V. et al. Comparação entre técnicas de classificação digital de imagens para detecção de mudanças do uso e cobertura da terra. Revista Brasileira de Cartografia, v. 62 n.04, 2010. Disponível em: < http://www.lsie.unb.br/rbc/index.php/rbc/article/view/227/214 >. Acesso em: 16 maio 2014.

FLORENZANO, T. G. Iniciação em Sensoriamento Remoto. 3. ed. São Paulo: Oficina de Textos, 2011.

GARCEZ, N. L; ALVARES, A. G. Hidrologia. 2. ed. São Paulo: Edgard Blucher, 2013.

GOUVEIA, R. G. L. de et al. Aplicação do índice de transformação antrópica na análise multitemporal da bacia do córrego do Bezerro Vermelho em Tangará da Serra-MT. Revista Árvore, v.37, n.6, p. 1045-1054. Disponível em: <http://www.scielo.br/pdf/rarv/v37n6/06.pdf>. Acesso em: 21 maio 2014.

IBGE, INSTITUTO BRASILEIRO DE GEOGRAFIA E ESTATÍSTICA.Censo Demográfico. Rio de Janeiro: IBGE, 2010. Disponível em: <http://www.cidades.ibge.gov.br/xtras/perfil.php?lang\&codmun $=315560 \&$ search=minas-gerais\%7Crio-pardo-de-minas $>$. Acessado em 09/03/2014.

KRAVCHENKO, A. Aerofotointerpretação - Fotografia Aérea à Serviço da Agricultura. Goiânia, GO: Escola de Agronomia - UFG, 1998.

LEITE, M. E.; ALMEIDA, J. L.; SILVA, R. F. Análise espaço-temporal do eucalipto no Norte de Minas Gerais nos anos de 1986, 1996 e 2010. Geotextos (Online), v. 8, n.2, p. 59-74, dez. 2012. Disponível em: <http://www.portalseer.ufba.br/index.php/geotextos/article/view/5931/4645> Acesso em: 15 mar. 2014.

LORENÇO, J. C. et al. Identificação de fatores de vulnerabilidade ambiental na floresta do louzeiro em Campina Grande-PB. POLÊM!CA,v. 12, n.2, p.274-283, abr/jun. 2013. Disponível em: <file:///C:/Users/Home/ Downloads/6429-24187-1-PB.pdf>. Acesso em: 01 jun. 2014.

LIMA, F. A. et al. Utilização do Sistema de Informações Geográficas Terraview para delimitação da bacia hidrográfica do Rio Vieira, Montes Claros - MG. In: Simpósio Regional de Geoprocessamento e Sensoriamento Remoto - Geonordeste, VI., 2012, Aracaju. Anais... Aracaju: 2008. Disponível em: <http://www. cvmn.com.br/HTML/Arquivos/Artigos/00220_025704.pdf> Acesso em: 10/Fev/2014.

MACHADO, P. J. de O.; TORRES, F. T. P. Introdução á Hidrogeografia. 1. ed. São Paulo: Cengage Learning, 2012.

MARTINS, S. L. et al. Análise multitemporal por imagem TM do uso e ocupação do solo na região nordeste da rodovia BR-319. In: Simpósio Brasileiro de Sensoriamento Remoto, XVI., 2013, Foz do Igaçu, Anais... Foz do Iguaçu: INPE, 2013. p. 1782-1789. Disponível em: <http://www.dsr.inpe.br/sbsr2013/files/p0902.pdf> Acesso em: 10 fev. 2014.

MENESES, P. R. Princípios do Sensoriamento Remoto. In: .; ALMEIDA, T. (Orgs.). Introdução ao Processamento de Imagens de Sensoriamento Remoto. Brasília: UNB, CNPq: 2012.

.; SANO, E. E. Classificação pixel a pixel de imagens. In: .; ALMEIDA, T. (Orgs.). Introdução ao Processamento de Imagens de Sensoriamento Remoto. Brasília: UNB, CNPq: 2012. 
NARDINI, R. C.; CAMPOS, S,; FELIPE, A. C. SIG Aplicado na caracterização morfométrica da microbacia do Ribeirão Morro Grande - BOFETE, SP. In: Fórum Ambiental da Alta Paulista, IX., 2013, Tupã. Anais... Tupã: 2013, p. 211-226. Disponível em: <file:///C:/Users/Home/Downloads/641-1288-1-SM.pdf>. Acesso em: 10 mar. 2014.

NERY, C. V. M. et al. Avaliação das Técnicas de Classificação MAXVER, MAXVER - ICM e Distância Mínima Euclidiana de acordo com Índice Kappa. Revista Brasileira de Geografia Física, v. 06, n. 02, p. 320 328, set. 2013. Disponível em: <http://www.revista.ufpe.br/rbgfe/index.php/revista/article/view/635/403>. Acesso em: 04 jan. 2014.

Aplicação do Novo Código Florestal na Avaliação das Áreas de Preservação Permanente em Topo de Morro na Sub-Bacia do Rio Canoas no Município de Montes Claros/MG. Revista Brasileira de Geografia Física, v. 06, n. 06, p. 1673-1688, nov. 2013. Disponível em: <http://www.revista.ufpe.br/rbgfe/index.php/ revista/article/viewArticle/633> Acesso em: 15 Mar. 2014.

NOVO, E. L. M. Sensoriamento Remoto: Princípios e aplicações. 4.ed. São Paulo: Blucher, 2010.

OLIVEIRA, P. T. S. de. et al. Caracterização morfométrica de bacias hidrográficas através de dados SRTM. Revista Brasileira de Engenharia Agrícola Ambiental, v.14, n. 8, p. 819-825, mar. 2010. Disponível em: <http://www.scielo.br/pdf/rbeaa/v14n8/v14n08a05.pdf> Acesso em: 27 maio 2014.

PINTO, N. de S.; HOLTZ, A. C. T.; MARTINS, J. A. Hidrologia Básica. 1. ed. São Paulo: Edgard Blucher, 1976.

PONZONI, F. J.; SHIMABUKURO, Y. E.; KUPLICH, T. M. Sensoriamento remoto da vegetação. 2. ed. São Paulo: Oficina de textos, 2012.

REMPEL, C. Aplicação do Sensoriamento Remoto para Determinação da Evolução da Mata Nativa da Bacia Hidrográfica do Rio Forqueta - RS, entre 1985 e 1995. 2000. 85f. Dissertação (Mestrado) - Universidade Federal do Rio Grande do Sul, Rio Grande do Sul, 2000. Disponível em:< http://www.lume.ufrgs.br/bitstream/handle/10183/11232/000294564.pdf?sequence=1>. Acesso em: 01 jun. 2014.

STRAHLER, A. N. Quantitative analysis of watershed geomorpholo- gy. Transaction of American Geophysical Union, v.38, p.913-920, dec. 1957.

TUCCI, C. E. M.; MENDES C. A. Avaliação Ambiental Integrada de Bacia Hidrográfica. 2. ed. Brasília: MMA, 2006. Disponível em: < http://www.mma.gov.br/estruturas/sqa_pnla/_arquivos/sqa_3.pdf >. Acesso em: 18 maio 2014.

VILLELA, S. M.; MATTOS, A. Hidrologia aplicada. São Paulo: McGRAW- Hill do Brasil, 1975.

VILELA, M. de F. et al. Mapeamento e análise da dinâmica de uso e da cobertura do solo em comunidades tradicionais do alto Rio Pardo, Minas Gerais. - Boletim de desenvolvimento e Pesquisa, Planaltina, DF: Embrapa Cerrados, 2009.

ZACCHI, R. C.; FARIA, M. M.; FERREIRA, E. S. Fatores morfométricos como condicionantes da ocorrência de enchentes na bacia do córrego Serafim, sub- bacia do rio Paraibuna, Juiz de Fora, MG. Boletim do Observatório Ambiental Alberto Ribeiro Lamego, v.6, n.1, p.151-160, jan/jun. 2012. Disponível em: <file:///C:/Users/Home/Downloads/2703-6945-2-PB.pdf>. Acesso em: 18 maio 2014. 